\section{Frost-acclimation of photosynthesis in overwintering Mediterranean holm oak, grown in Central Europe}

\author{
Ellen Pflug, ${ }^{1}$ Wolfgang Brüggemann ${ }^{1,2}$ \\ 1Department of Ecology, Evolution and \\ Diversity, Goethe University Frankfurt, \\ 2Biodiversity and Climate Research \\ Centre, Frankfurt, Germany
}

\section{Abstract}

As a consequence of global change, forestry in Central Europe has to expect and be prepared for an increase of hot and dry summers in the near future. In two model plantations of the Mediterranean holm oak (Quercus ilex L.) in Central Europe (Rhine-Main basin) we tested its potential as a future forestry tree for drought-threatened stands by studying its overwintering strategy under harsh winter conditions. During prolonged frost periods, chronic photoinhibition was developed, which lasted until the end of the frost period. Nearly all plants survived minimum temperatures of 16 to $-18^{\circ} \mathrm{C}$ and their photosynthetic apparatus recovered completely during late winter. A detailed study of the temperature dependence of chlorophyll (chl) fluorescence parameters of the OJIP test revealed statistically significant correlations between minimum temperature and maximum quantum yield of primary photochemistry (Fv/Fm), absorption rate/reaction centre (ABS/RC), dissipation rate/reaction centre $\left(\mathrm{DI}_{0} / \mathrm{RC}\right)$ and electron transport rate/reaction centre $\left(\mathrm{ET}_{0} / \mathrm{RC}\right)$ as well as with the deepoxidation state (DES) of the xanthophyll pigments. The DES correlated with $\mathrm{Fv} / \mathrm{Fm}, \mathrm{ABS} / \mathrm{RC}, \mathrm{DI}_{0} / \mathrm{RC}$ and $\mathrm{ET}_{0} / \mathrm{RC}$. It is concluded, that from the point of view of the winter hardiness of the photosynthetic apparatus, $Q$. ilex should be further investigated as a potential future forestry tree also for very dry and warm stands in Central Europe under the scenarios of climate change.

\section{Introduction}

In the course of Global Climate Change, it is expected that in the long run southern European tree species will increasingly be favoured in the warm and dry areas in Central Europe over the nowadays dominating beech. ${ }^{1}$ In forestry, this will lead to a slow change in tree species composition towards an increas- ing abundance of evergreen species. ${ }^{2,3}$ However, natural migration rates of South European species may not be sufficient to fill gaps obtained by local dieback of local tree species. ${ }^{4}$ Therefore, forestry researchers are currently evaluating and testing various foreign tree species for their potential as future forestry species. ${ }^{5}$ Planting North American tree species like (deciduous) Quercus rubra and (evergreen) Pseudotsuga menziesii to minimize future Climate Change-prone risks in economic forestry might alter the existing ecosystems significantly. The alternative concept of human-aided migration of South European tree species and/or ecotypes into already warm and dry Central European stands can be regarded as a measure, which might enable a smooth transformation of existing, but threatened forest communities to mixed, future-suited forest systems. ${ }^{6}$ In this context, we evaluate deciduous and evergreen Quercus species from the Mediterranean for their potential as forestry trees, ${ }^{7}$ including their potential for winter survival under the actual still harsher winter conditions as compared to the Mediterranean basin.

Evergreen tree species from arctic/alpine biomes are known to acclimate to severe winter conditions by a mechanism called chronic photoinhibition, which is characterized by a decrease of predawn maximum quantum yield of primary photochemistry, accompanied by high deepoxidation states of the xanthophyll pigments (sustained high AZNAZ ratios).${ }^{8}$ It is interpreted as a means to allow for harmless heat dissipation even at early morning, when a combination of low temperatures and light otherwise would lead to photooxidative damage. This behaviour has also punctually been documented in field studies of the evergreen Quercus ilex L. in Spain, where leaf samples have been analysed at single dates during winter in connection with moderate frost events (4 to $\left.-8^{\circ} \mathrm{C}\right) .{ }^{9-11}$ However, northern ecotypes of the species may tolerate much lower winter temperatures down to approx. $-20^{\circ} \mathrm{C} .{ }^{12} Q$. ilex is successfully cultivated in parks in warmer places in central Europe and Britain and is known to colonize the Atlantic coast up to Brittany. It has therefore been suggested, that Q. ilex together with other (deciduous) Mediterranean oak species may play a future role in forestation experiments in Central Europe with respect to expected climate change effects on existing oak stands, especially on already dry soil conditions. ${ }^{7}$

The analysis of the fast induction curve of chl fluorescence from PS II (so-called OJIP-test), ${ }^{13}$ allows the dissection of different steps of exciton/electron movements in the initial phase of the electron transport chain. It has been used to study stress physiology of trees ${ }^{14-16}$ and has recently also been introduced for the assess-
Correspondence: Wolfgang Brüggemann, Department of Ecology, Evolution and Diversity, Goethe University Frankfurt am Main, Siesmayerstr. 70 B, D-60323 Frankfurt, Germany. Tel. +49.69.7982.4745 - Fax: +49.69.7982.4822.

E-mail: w.brueggemann@bio.uni-frankfurt.de

Key words: chlorophyll fluorescence, OJIP test, xanthophyll cycle.

Acknowledgements: the present study was financially supported by the research funding programme LOEWE - Landes-Offensive zur Entwicklung Wissenschaftlich-ökonomischer Exzellenz of Hesse's Ministry of Higher Education, Research, and the Arts. This work was carried out as part of the Diploma thesis of E. Pflug under the direct supervision of $\mathrm{W}$. Brüggemann. All experiments were carried out and evaluated by E. Pflug under the direct supervision of W. Brüggemann. The MS was written by W. Brüggemann based on the delivered Diploma thesis of E. Pflug (University of Frankfurt, 2010).

Received for publication: 13 January 2011. Revision received: 21 October 2011.

Accepted for publication: 19 January 2012.

This work is licensed under a Creative Commons Attribution NonCommercial 3.0 License (CC BYNC 3.0).

(C) Copyright E. Pflug and W. Brüggemann, 2012

Licensee PAGEPress srl, Italy

International Journal of Plant Biology 2012; 3:e1 doi:10.4081/pb.2012.e1

ment of frost tolerance of winter cereals. ${ }^{17,18} \mathrm{To}$ the authors' knowledge, so far no thorough study of the effects of chronic photoinhibition in evergreen broadleaf plants on the OJIP parameters has been published.

The aim of the present study was to analyse the direct effect of low, subzero temperatures under Central European field conditions on $Q$. ilex PS II functionality not on a punctual base, but throughout the winter period. It is known, that in the Mediterranean basin, Q. ilex uses the (usually) mild winter conditions for continuous photosynthetic activity, whenever allowed by climatic conditions. ${ }^{10-19}$ We hypothesize that $Q$. ilex may tolerate not only punctual frost episodes like in the Mediterranean basin, but also severe and long-lasting subzero temperatures in the field by the so-called chronic photoinhibition mechanism without inducing further damage. To study this, we analysed the performance of $Q$. ilex PS II in experimental plantations under two different frost and one frost-free regime throughout the unusually severe winter 2009/10 in the RhineMain valley with the OJIP test. 


\section{Materials and Methods}

\section{Plant material and experimental sites}

Two-year old plants of Q. ilex ssp. ilex (certified seed material F-QIL702 Provence), collected from a population close to the border of Provence/Languedoc and supplied by Darmstädter Forstbaumschule (Darmstadt, Germany) were sown in 2004 and planted at the Botanical Garden of the University of Frankfurt $\left(50^{\circ} 07.564^{\prime} \mathrm{N}, 8^{\circ} 39.495^{\prime} \mathrm{E}\right.$, site denomination: FR) in 2006 on a fully sunnyexposed site in common garden soil. These plants were exposed to full sunlight until approximately $5 \mathrm{pm}$ in May. 86 out of 88 plants survived all winters until 2009 without damage. In October 2009, at age 5 yo, 4 of them (ca. 1-1.5 m high) were transplanted with their root system as intact as possible into a foliar greenhouse erected on the same soil, which was kept frost-free during winter (site denomination: FRFF) and 6 of them were transplanted into an experimental forest site in the vicinity of Rüsselsheim Germany $\left(49^{\circ} 57.232\right.$ ' N, $8^{\circ} 24.914^{\prime} \mathrm{E}$, site denomination: RU). All transplanted plants were irrigated regularly until onset of autumn/winter precipitation to prevent drought stress from root damage due to the transplantation process.
The plants at FRFF were irrigated once or twice weekly throughout the winter.

The Rüsselsheim site is a sparse Pinus sylvestris forest (ca. 60 yo) on an inland sand dune, dominated by Rubus fruticosus aggr. and with natural rejuvenation of Quercus robur, $Q$. rubra (from an adjacent plantation), Prunus serrotina, Crataegus monogyna, Robinia pseudoacacia and Betula pendula. The average ground water table lies at $-5.5 \mathrm{~m}$ below ground level. At the RU and at the FRFF site, the average PFDs reaching the plants were approximately $60-70 \%$ of full sunlight by partial shading by the pines and by the absorbance of the foliar greenhouse, respectively. Three randomly chosen plants of average size were identified from the population left at the Frankfurt frost-exposed site and monitored throughout the winter. Thus, data sets of FR plants rely on 3, those on FRFF on 4 and those on RU on 6 biological replicates. In general, per biological replicate and measuring date, 10 (fluorescence) or 2 (AZ/NAZ) technical replicates (individual leaves) were analysed. Data for global radiation were obtained from Deutscher Wetterdienst, Offenbach, Germany, for the closest by measuring station Geisenheim (ca. $30 \mathrm{~km}$ west of RU and ca. 45 $\mathrm{km}$ west of FR).

Data for temperature were either recorded at FR or taken from Deutscher Wetterdienst, Offenbach, Germany, for Frankfurt Airport (ca. $8 \mathrm{~km}$ east of RU).

\section{Chlorophyll fluorescence}

\section{measurements}

On the evening before each measuring day, twigs of $Q$. ilex were covered in black fabric to prevent light acclimation of the leaves during the following dusk. On the next morning at predawn, measurements were started by attaching darkening leaf clips to the leaves prior to withdrawing the fabric. Chlorophyll fluorescence induction curves were measured with a Pocket PEA (HansaTech, Germany) and a saturating pulse of $3500 \mu \mathrm{mol}$ quanta $\mathrm{m}^{-2} \mathrm{~s}^{-1}$ red light $(650 \mathrm{~nm})$. Data were analysed using the PEA plus program (HansaTech, Germany) in the mode, which uses the extrapolated $\mathrm{F}_{0}$ value (not the $F_{0}=F(50 \mu s)$ mode). The 0JIP-values of chl fluorescence were obtained at 0 (extrapolated), 2, 300 and $900 \mathrm{~ms}$, respectively. The initial phase of the fluorescence induction curve was represented by the data extracted at $50 \mu \mathrm{s}, 100$ $\mu \mathrm{s}, 300 \mu \mathrm{s}, 2 \mathrm{~ms}, 30 \mathrm{~ms}$, given in Tables 1-3.

Representative induction curves were normalized as done e.g. by Van Heerden et al. ${ }^{20}$ and others as $\mathrm{F}_{\text {normalized }}=\left[\mathrm{F}(\mathrm{t})-\mathrm{F}_{0}\right] /\left(\mathrm{F}_{\mathrm{M}}-\mathrm{F}_{0}\right)$ and the shape of the $\mathrm{F}_{\text {normalized }} v s$. $\log \mathrm{t}$ curves was analysed. It turned out that induction curves with $\left(\mathrm{F}_{\mathrm{M}}-\mathrm{F}_{0}\right)<600$ units did not express the $\mathrm{J}$ and I steps in a satisfying manner; hence, they were regarded as fault datasets and excluded from further analysis. Such data sets occurred occasionally in frost-exposed plants (5-13\% of all measurements in FR and RU) between

Table 1. Mean values of raw fluorescence intensities of the Pocket-PEA measurements at T0-T5 and for the maximum fluorescence (FM) for all data points in Figures 3-4 obtained at the Rüsselsheim site (RU), at the Frankfurt site outdoors (FR) and at the Frankfurt site under frost-free conditions (FRFF); average SDs were $17-28 \%$ of the means.

\begin{tabular}{|c|c|c|c|c|c|c|c|c|}
\hline site & date & $\begin{array}{c}\text { F0 } \\
\text { (extrapolated) }\end{array}$ & $\begin{array}{c}\mathrm{F1} \\
(0.05 \mathrm{~ms})\end{array}$ & $\begin{array}{c}\text { F2 } \\
(0.1 \mathrm{~ms})\end{array}$ & $\begin{array}{c}\text { F3 } \\
(0.3 \mathrm{~ms})\end{array}$ & $\begin{array}{c}\text { F4 } \\
(2 \mathrm{~ms})\end{array}$ & $\begin{array}{c}\text { F5 } \\
(30 \mathrm{~ms})\end{array}$ & $\begin{array}{c}\text { FM } \\
\text { (900 ms) }\end{array}$ \\
\hline \multirow[t]{10}{*}{$\mathrm{RU}$} & 19.11.2009 & 4885 & 5062 & 5235 & 5964 & 10159 & 18399 & 25635 \\
\hline & 23.12.2009 & 4571 & 4656 & 4750 & 5086 & 6941 & 9641 & 12160 \\
\hline & 05.01 .2010 & 4004 & 4062 & 4125 & 4345 & 5496 & 6809 & 7583 \\
\hline & 10.01 .2010 & 2957 & 5008 & 5058 & 5241 & 6090 & 7120 & 7817 \\
\hline & 27.01 .2010 & 4160 & 4200 & 4243 & 4390 & 5142 & 6054 & 6577 \\
\hline & 02.02.2010 & 4456 & 4513 & 4571 & 4771 & 5680 & 6777 & 7632 \\
\hline & 18.02.2010 & 3649 & 4061 & 4094 & 4192 & 4701 & 5463 & 5854 \\
\hline & 26.02.2010 & 3976 & 4036 & 4103 & 4333 & 5481 & 7173 & 7942 \\
\hline & 25.03 .2010 & 3640 & 3718 & 3796 & 4089 & 5594 & 7624 & 8657 \\
\hline & 29.04 .2010 & 3335 & 3454 & 3577 & 4027 & 6067 & 10391 & 13606 \\
\hline \multirow[t]{7}{*}{ FR } & 26.11.2009 & 5077 & 5294 & 5509 & 6420 & 11426 & 20017 & 27924 \\
\hline & 13.01.2010 & 4454 & 4530 & 4606 & 4898 & 6371 & 8389 & 9715 \\
\hline & 03.02.2010 & 3953 & 4017 & 4087 & 4326 & 5504 & 7287 & 8688 \\
\hline & 17.02 .2010 & 3566 & 3593 & 3624 & 3722 & 4174 & 4858 & 5299 \\
\hline & 25.02 .2010 & 3891 & 3956 & 4021 & 4262 & 5545 & 7729 & 8883 \\
\hline & 11.03 .2010 & 3373 & 3397 & 3423 & 3502 & 3873 & 4519 & 4938 \\
\hline & 28.04 .2010 & 3909 & 4051 & 4191 & 4771 & 7953 & 13807 & 19378 \\
\hline \multirow[t]{7}{*}{ FRFF } & 26.11.2009 & 5233 & 5443 & 5648 & 6397 & 11663 & 21758 & 30471 \\
\hline & 13.01 .2010 & 3800 & 3912 & 4022 & 4480 & 7898 & 15049 & 22052 \\
\hline & 03.02.2010 & 4553 & 4707 & 4868 & 5493 & 9240 & 17420 & 24022 \\
\hline & 17.02.2010 & 4856 & 5023 & 5181 & 5878 & 9994 & 17389 & 22727 \\
\hline & 25.02.2010 & 4503 & 4651 & 4804 & 5440 & 9877 & 18688 & 26333 \\
\hline & 11.03 .2010 & 3551 & 3625 & 3711 & 4004 & 5819 & 10457 & 15701 \\
\hline & 28.04.2010 & 4929 & 5106 & 5283 & 5975 & 9243 & 17959 & 23805 \\
\hline
\end{tabular}


January and March 2010, in particular in three out of the six trees planted in the frost-exposed site at RU. In the latter group, the frequency of such fault data sets increased up to $40 \%$ by late March 2010 in two of these trees, which turned out to be damaged by the winter conditions and were hence completely excluded from further analysis. The following parameters derived from the 0JIP test are used in this contribution: ${ }^{13,21,22} \mathrm{Fv} / \mathrm{Fm}$ (maximum quantum yield of primary photochemistry in the dark-adapted state), $\mathrm{ABS} / \mathrm{RC}$ [absorbance per reaction centres (RC)], $\mathrm{S}_{\mathrm{m}}$ [i.e. normalized area, ${ }_{0}^{\mathrm{tFM}}\left(\mathrm{F}_{\mathrm{M}^{-}}\right.$ $\left.\left.F_{t}\right) d t /\left(F_{M}-F_{0}\right)\right]$, which is regarded as a measure of the energy needed to close all reaction centres during the OJIP phase, and which can be interpreted as the electron acceptor capacities of the $\mathrm{Q}_{\mathrm{A}}, \mathrm{Q}_{\mathrm{B}}$ and $\mathrm{PQ}$ pools, ${ }^{21} \mathrm{TR}_{0} / \mathrm{RC}$ (maximum trapping rate of active $\mathrm{RC}$ ), $\mathrm{DI}_{0} / \mathrm{RC}$ (effective energy dissipation of active $\mathrm{RC}$ ), $\mathrm{ET}_{0} / \mathrm{RC}$ (electron transport rate of active $\mathrm{RC}$ ) and $\mathrm{ET}_{0} / \mathrm{TR}_{0}$ (the probability to feed electrons residing on $Q_{A}^{-}$into the electron chain beyond PSII).

\section{Xanthophyll cycle pigments}

Leaf discs of $14 \mathrm{~mm}$ diameter were collected in the dark (pre-dawn and night measurements) or under the prevailing natural illumi- nation (day measurements in Figure $1 \mathrm{C}$ and G) from the same twigs, on which PEA measurements were performed and immediately frozen in liquid $\mathrm{N}_{2}$. Pigment extraction in acetone in the presence of $\mathrm{Na}$-ascorbate and analysis by HPLC were performed as described by De las Rivas et al. ${ }^{23}$ in the presence of $0.7 \%(\mathrm{v} / \mathrm{v})$ triethylamine in both elution solvents (J. Abadia, CSIC Zaragoza, personal communication) and xanthophyll pigments were calculated according to Färber et $a l^{24}$ The deepoxidation state of the xanthophyll pigments viola (V) - anthera (A) and zeaxanthin $(\mathrm{Z})$ was calculated as $\mathrm{AZNAZ}=$ $([\mathrm{A}]+[\mathrm{Z}]) /([\mathrm{V}][\mathrm{A}]+[\mathrm{Z}])$, with $[\mathrm{V}],[\mathrm{A}]$ and

Table 2. Mean values of raw fluorescence intensities of the Pocket-PEA measurements at T0-T5 and for the maximum fluorescence (FM) for all data points in Figures 1-2 at the Frankfurt site outdoors (FR) and at the Frankfurt site under frost-free conditions (FRFF); Measuring Date: 14.01.2010.

\begin{tabular}{|c|c|c|c|c|c|c|c|c|}
\hline site & time & $\begin{array}{c}\mathrm{F} 0 \\
\text { (extrapolated) }\end{array}$ & $\begin{array}{c}\text { F1 } \\
(0.05 \mathrm{~ms})\end{array}$ & $\begin{array}{c}\text { F2 } \\
(0.1 \mathrm{~ms})\end{array}$ & $\begin{array}{c}\text { F3 } \\
(0.3 \mathrm{~ms})\end{array}$ & $\begin{array}{c}\mathrm{F4} \\
(2 \mathrm{~ms})\end{array}$ & $\begin{array}{c}\text { F5 } \\
(30 \mathrm{~ms})\end{array}$ & $\begin{array}{c}\text { FM } \\
(900 \mathrm{~ms})\end{array}$ \\
\hline \multirow[t]{9}{*}{ FR } & 09:00 & 3959 & 4027 & 4093 & 4334 & 5525 & 7255 & 8351 \\
\hline & 12:00 & 3544 & 3628 & 3673 & 3801 & 4555 & 5922 & 6998 \\
\hline & 15:00 & 3502 & 3528 & 3562 & 3658 & 4193 & 5094 & 5717 \\
\hline & 18:00 & 3287 & 3320 & 3359 & 3484 & 4278 & 5466 & 6198 \\
\hline & 21:00 & 3726 & 3784 & 3848 & 4076 & 5447 & 7263 & 8391 \\
\hline & 00:00 & 5281 & 5405 & 5525 & 6014 & 8493 & 10932 & 12800 \\
\hline & 03:00 & 3871 & 3946 & 4025 & 4305 & 5950 & 8049 & 9531 \\
\hline & 06:00 & 3911 & 3988 & 4070 & 4365 & 6096 & 8242 & 9701 \\
\hline & 09:00 & 4094 & 4173 & 4254 & 4557 & 6362 & 8616 & 10127 \\
\hline \multirow[t]{9}{*}{ FRFF } & 09:00 & 4427 & 4578 & 4738 & 5346 & 9621 & 17463 & 24981 \\
\hline & 12:00 & 3849 & 3949 & 4055 & 4487 & 7695 & 14450 & 20469 \\
\hline & 15:00 & 4073 & 4203 & 4327 & 4863 & 8862 & 15660 & 22020 \\
\hline & 18:00 & 3550 & 3646 & 3746 & 4141 & 7680 & 13726 & 19930 \\
\hline & 21:00 & 4119 & 4255 & 4387 & 4969 & 10065 & 17216 & 23851 \\
\hline & 00:00 & 5139 & 5370 & 5590 & 6611 & 14130 & 22363 & 29670 \\
\hline & 03:00 & 3673 & 3782 & 3890 & 4348 & 8490 & 15312 & 21393 \\
\hline & 06:00 & 4103 & 4238 & 4373 & 4960 & 10086 & 17723 & 24217 \\
\hline & 09:00 & 4243 & 4396 & 4546 & 5191 & 10509 & 18113 & 24783 \\
\hline
\end{tabular}

Table 3. Mean values of raw fluorescence intensities of the Pocket-PEA measurements at T0-T5 and for the maximum fluorescence (FM) for all data points in Figures 1-2 obtained at the Frankfurt site outdoors (FR) and at the Frankfurt site under frost-free conditions (FRFF); Measuring Date 25.05.2010.

\begin{tabular}{|c|c|c|c|c|c|c|c|c|}
\hline site & time & $\begin{array}{c}\text { F0 } \\
\text { (extrapolated) }\end{array}$ & $\begin{array}{c}\text { F1 } \\
(0.05 \mathrm{~ms})\end{array}$ & $\begin{array}{c}\text { F2 } \\
(0.1 \mathrm{~ms})\end{array}$ & $\begin{array}{c}\text { F3 } \\
(0.3 \mathrm{~ms})\end{array}$ & $\begin{array}{c}\text { F4 } \\
\text { (2 ms) }\end{array}$ & $\begin{array}{c}\text { F5 } \\
\text { (30 ms) }\end{array}$ & $\begin{array}{c}\text { FM } \\
\text { (900 ms) }\end{array}$ \\
\hline \multirow[t]{9}{*}{ FR } & 09:00 & 3343 & 3456 & 3573 & 4014 & 6597 & 12442 & 17643 \\
\hline & $12: 00$ & 3455 & 3586 & 3721 & 4212 & 6948 & 12545 & 17631 \\
\hline & $15: 00$ & 3508 & 3655 & 3798 & 4357 & 7354 & 12693 & 17573 \\
\hline & 18:00 & 3423 & 3563 & 3702 & 4273 & 7759 & 13168 & 17272 \\
\hline & $21: 00$ & 3209 & 3341 & 3467 & 4014 & 7956 & 14219 & 17844 \\
\hline & 00:00 & 3997 & 4203 & 4402 & 5307 & 11590 & 18990 & 23124 \\
\hline & 03:00 & 3560 & 3729 & 3899 & 4658 & 10263 & 16642 & 20532 \\
\hline & 06:00 & 3189 & 3322 & 3458 & 4021 & 7990 & 13857 & 17476 \\
\hline & 09:00 & 3770 & 3909 & 4048 & 4595 & 7750 & 13387 & 17925 \\
\hline \multirow[t]{9}{*}{ FRFF } & 09:00 & 3982 & 4130 & 4268 & 4842 & 8101 & 15665 & 20669 \\
\hline & $12: 00$ & 4095 & 4245 & 4403 & 5011 & 8353 & 14142 & 20044 \\
\hline & $15: 00$ & 4238 & 4394 & 4559 & 5175 & 8193 & 12301 & 17975 \\
\hline & 18:00 & 3987 & 4121 & 4267 & 4803 & 8161 & 15422 & 19951 \\
\hline & $21: 00$ & 3637 & 3761 & 3896 & 4446 & 8686 & 15795 & 19668 \\
\hline & 00:00 & 4398 & 4590 & 4769 & 5592 & 11389 & 19114 & 23086 \\
\hline & 03:00 & 4124 & 4287 & 4442 & 5148 & 10643 & 18431 & 22594 \\
\hline & 06:00 & 3947 & 4080 & 4204 & 4744 & 8861 & 16638 & 21281 \\
\hline & 09:00 & 4232 & 4369 & 4509 & 5052 & 8257 & 15929 & 21216 \\
\hline
\end{tabular}


[Z] being the respective relative molar concentrations of the xanthophylls in the leaf extracts. ${ }^{8}$

\section{Statistical analysis}

Correlations between chl fluorescence parameters and $\mathrm{T}_{\min }$ or AZ/NAZ were calculated with the inherent statistic software of the GraphPad PRISM ${ }^{\circledR}$ software. The Spearman25 rank correlation analysis was chosen, since it takes into account whether the compared data sets follow a monotonous function (i.e. including the possibility of threshold values of one parameter, i.e. temperature, after which the dependent parameter, i.e. AZNAZ or a fluorescence parameter, shows a strong change). It does not assume linear correlations, which are the basis of the Pearson correlation analysis, since no a priori no linearity between the studied parameters needs to exist. The correlation coefficients in Table 4 contain the respective levels of significance [i.e. $<0.05\left(^{*}\right)$ and $<0.01$ $(* *)]$.

\section{Results}

\section{Diurnal courses of electron flow and energy dissipation}

To assess, whether chronic photoinhibition occurred during winter frost periods, the diurnal and nocturnal patterns of chl fluorescence parameters and of AZ/VAZ were monitored during a frost period ( $\mathrm{T}_{\min }$ of -7 to $-1^{\circ} \mathrm{C}$ ) in January 2010 under cloudy sky, to prevent strong dynamic photoinhibition obscuring chronic effects. Fv/Fm of the frostexposed plants (Figure 1B) showed clear chronic and - on top of it - moderate dynamic photoinhibition, which was accompanied by a slight diurnal rise and nocturnal decrease of the AZ/NAZ ratio, starting from already very high predawn values (Figure 1C). In contrast, in spring, under non-frost conditions, practically no diurnal course of Fv/Fm was observed, while sun-exposed leaves revealed the typical diurnal pattern of AZ/VAZ (Figure 1F, G). Dissection of the initial rise of the fluorescence induction curve showed that energy dissipation $\left(\mathrm{DI}_{0} / \mathrm{RC}\right)$ revealed a similar pattern as the AZ/NAZ curves, with very high values in plants kept outdoor in winter (Figure 1D).

The dissection of the initial rise of the fluorescence induction curve furthermore revealed increased $\mathrm{ABS} / \mathrm{RC}, \mathrm{TR}_{0} / \mathrm{RC}$ and $\mathrm{ET}_{0} / \mathrm{RC}$ values for frost-exposed leaves (Figure $2 \mathrm{~A}-\mathrm{D}$ ) and slight diurnal patterns of these parameters under spring conditions (Figure $2 \mathrm{E}-\mathrm{H}$ ). Concerning the normalized area parameter $\mathrm{S}_{\mathrm{m}}$, plants exposed to frost outside showed a lower level than those sheltered in the frost-free greenhouse. However, when compared to plants measured in spring, the plants from the frost-free greenhouse revealed an increased level of $S_{m}$ (Figure $2 C, G$ ).

\section{Semi-annual courses of electron flow and energy dissipation}

During winter 2009/10, very low outdoor temperatures $\left(-16\right.$ to $\left.-18^{\circ} \mathrm{C}\right)$ were observed several times between mid-December and the end of February in the vicinity of the forest plot at Rüsselsheim (Figure 3A). This is close to the lethal temperature for Quercus ilex (i.e. $-22^{\circ} \mathrm{C}$ for the northernmost Italian ecotype from Lake Garda). ${ }^{12}$ In the Botanical Garden in Frankfurt, the city climate provided less severe temperature minima $\left(-14\right.$ to $\left.-16^{\circ} \mathrm{C}\right)$ and less frost days. In the frost-free greenhouse, the heating assured temperature fluctuations only between +10 and $+4^{\circ} \mathrm{C}$, frost did not occur. While, in the greenhouse and in the Botanical Garden, winter survival of aboveground parts of $Q$. ilex was

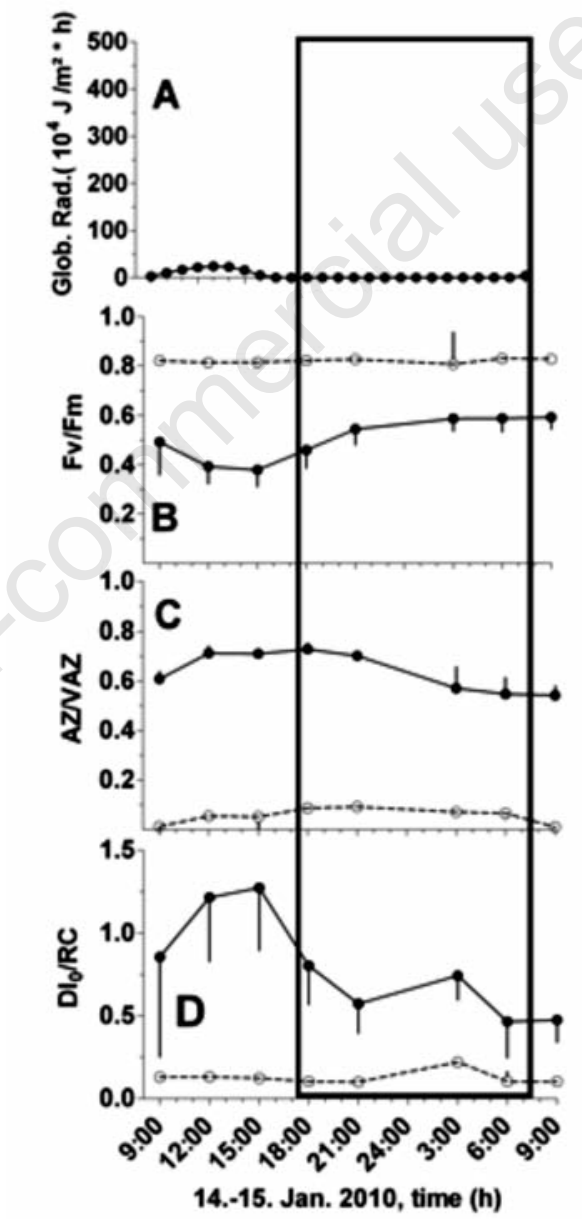

Figure 1. Diurnal courses of global radiation at Geisenheim, chl fluorescence parameters and AZ/VAZ in Q. ilex growing outdoors $(\bullet, F R)$ or in a frost-free foliar greenhouse $(O$, FRFF) at Frankfurt on 14.01.2010 (1A-D, $\mathrm{T}=-3^{\circ}$ to $+1^{\circ} \mathrm{C}$, heavily clouded) and on 25.05.2010 ( $1 \mathrm{E}-\mathrm{H}, \mathrm{T}=+13^{\circ}$ to $+25^{\circ} \mathrm{C}$, very sunny). Night periods are denoted by the black rectangles. Means $\pm S D ; n=10(A Z / V A Z: n=2)$ leaves (technical replicates) per three trees (biological replicates) analysed on each location. A, anthera; $Z$, zeaxanthin; V, viola; FR, Frankfurt; FRFF, Frankfurt, frost-free. 
strong increase of predawn AZNAZ (Figure 3D). After the first strong frost period at mid-december, and anti-parallel to the development of the Fv/Fm ratio, energy dissipation increased, more so in the RU than in the FR site.

The dissection of the initial induction curve of chl fluorescence (Figure 4) also revealed a strong increase of $\mathrm{ABS} / \mathrm{RC}$ (Figure $4 \mathrm{~B}$ ) and a moderate reversible increase of the trapping rate $\left(\mathrm{TR}_{0} / \mathrm{RC}\right.$, Figure $\left.4 \mathrm{C}\right)$ during the frost period, while the electron transport rate beyond $Q_{A}$ $\left(\mathrm{ET}_{0} / \mathrm{RC}\right.$ ) was hardly affected (Figure $4 \mathrm{E}$ ). In frost-free kept plants, increased values of up to 80 arbitrary units for $S_{m}$ were observed during the winter months, while the plants exposed to frost showed a tendency to decreased values, down to 40 arbitrary units, as had been the case in the analysis of the diurnal course in Figure 2. The probability of electron transport $\left(\mathrm{ET}_{0} / \mathrm{TR}_{0}\right.$, Figure $\left.4 \mathrm{~F}\right)$ slightly decreased in the trees in the forest and in the frost-exposed trees in the city, as compared to frost-free control trees.

The analyses of the correlations between the fluorescence parameters and minimum night temperatures or AZ/NAZ are shown in Table 4. Significant correlations (Spearman) were observed between Fv/Fm, AZ/NAZ, DI $\mathrm{I}_{0} / \mathrm{RC}$, $\mathrm{ABS} / \mathrm{RC}$ and $\mathrm{ET}_{0} / \mathrm{TR}_{0}$ with $\mathrm{T}_{\min }$ and between $\mathrm{Fv} / \mathrm{Fm}, \mathrm{DI}_{0} / \mathrm{RC}, \mathrm{ABS} / \mathrm{RC}$ and $\mathrm{ET}_{0} / \mathrm{TR}_{0}$ with AZ/VAZ.

\section{Discussion}

\section{Diurnal courses of energy dissipation and electron flow}

As reported for various evergreen species, ${ }^{8}$ the chronic winter photoinhibition (Figure 1B) was accompanied by a high sustained AZ/NAZ ratio, allowing for harmless energy dissipation (Figure 1C). On top, a minor diurnal oscillation was visible, antiparallel with the dynamic oscillation of Fv/Fm. Notably, this phenomenon was also strongly temperature (i.e. frost-) dependent and not an inherent characteristic of winter acclimated $Q$. ilex, since the frost-free plants showed no such increase of AZNAZ.

Apparently, the sustained high AZ/VAZ ratios allowed very efficient energy dissipation in the frost-exposed plants (Figure 1D), while, under spring conditions, the diurnal pattern of light induced Violaxanthin deepoxidation (Figure 1G) was reflected only in a slight diurnal pattern of energy dissipation efficiency (Figure 1H).

Under frost conditions, the dynamic photoinhibition imposed on the plants outdoors resulted in much higher ABS/RC values during daytime (Figure 2A), indicating either an increase of light absorbance (per leaf area) during day- time (e.g. by increasing antenna size) and/or a decrease of the concentration of active reaction centres. If compared to the diurnal fluctuation in unstressed leaves during late may (Figure $2 \mathrm{E}$ ), it becomes evident, that the natural diurnal course of the ABS/RC value by diurnal fluctuations in antenna size ${ }^{26}$ influences this parameter to a much lower extent. It is therefore concluded, that the high $\mathrm{ABS} / \mathrm{RC}$ values around 2.0 during daytime in Figure 2A are the result of a large amount of silent centres under frost conditions. ${ }^{21}$ The diurnal fluctuation of $\mathrm{ABS} / \mathrm{RC}$ in unstressed leaves was accompanied by small parallel increases in light trapping
$\left(\mathrm{TR}_{0} / \mathrm{RC}\right)$, normalized area $\left(\mathrm{S}_{\mathrm{m}}\right)$ and electron transport beyond $\mathrm{Q}_{\mathrm{A}}\left(\mathrm{ET}_{0} / \mathrm{RC}\right)$ during daytime (Figure 2F-H). Under winter conditions, however, these oscillations are diminished or absent (Figure 2B-2D) and the frost-treated plants revealed higher values of $\mathrm{TR}_{0} / \mathrm{RC}$ and $\mathrm{ET}_{0} / \mathrm{RC}$ and lower $\mathrm{S}_{\mathrm{m}}$ values than the frost-free treated ones. $S_{m}$, which can be interpreted as a measure of the capacity of the plastoquinone pool, had apparently increased in the winteracclimated, but frost free plants as compared to plants measured in spring (Figure 4). Under frost conditions, this effect was obviously lost. We suggest, that the differences in $\mathrm{TR}_{0} / \mathrm{RC}$ and

Table 4. Spearman correlation coefficients $\left(r_{s}\right)$ and significance levels of the xanthophyll deepoxidation state AZ/VAZ and the fluorescence parameters Fv/Fm, DI0/RC, ABS /RC and ETO/TRO with Tmin and AZ/VAZ. Correlations between $\mathrm{TR}_{0} / \mathrm{RC}, \mathrm{ET}_{0} / \mathrm{RC}$ and $S_{\mathrm{m}}$ with $T_{\min }$ or $A Z / V A Z$ were not significant.

$\begin{array}{lcccll}\text { us } & \text { Fv/Fm } & \text { AVNAZ } & \text { DIO/RC } & \text { ABS/RC } & \text { ETO/IR0 } \\ \mathrm{T}_{\min } & 0.65^{* *} & -0.77^{* *} & -0.68^{* *} & -0.65^{* *} & 0.69^{* *} \\ \text { AZNAZ } & -0.73^{*} & ---- & 0.78^{* *} & 0.80^{* *} & -0.72^{* *}\end{array}$

${ }^{*} \mathrm{P}<0.05,{ }^{* *} \mathrm{P}<0.01$. A, anthera; $\mathrm{Z}$, zeaxanthin; $\mathrm{V}$, viola; Fv/Fm, maximum quantum yield of primary photochemistry; DI0, dissipation rate; RC, reaction centre; $\mathrm{ABS}$, absorption rate; ET0, electron transport rate; TR0: trapping rate.
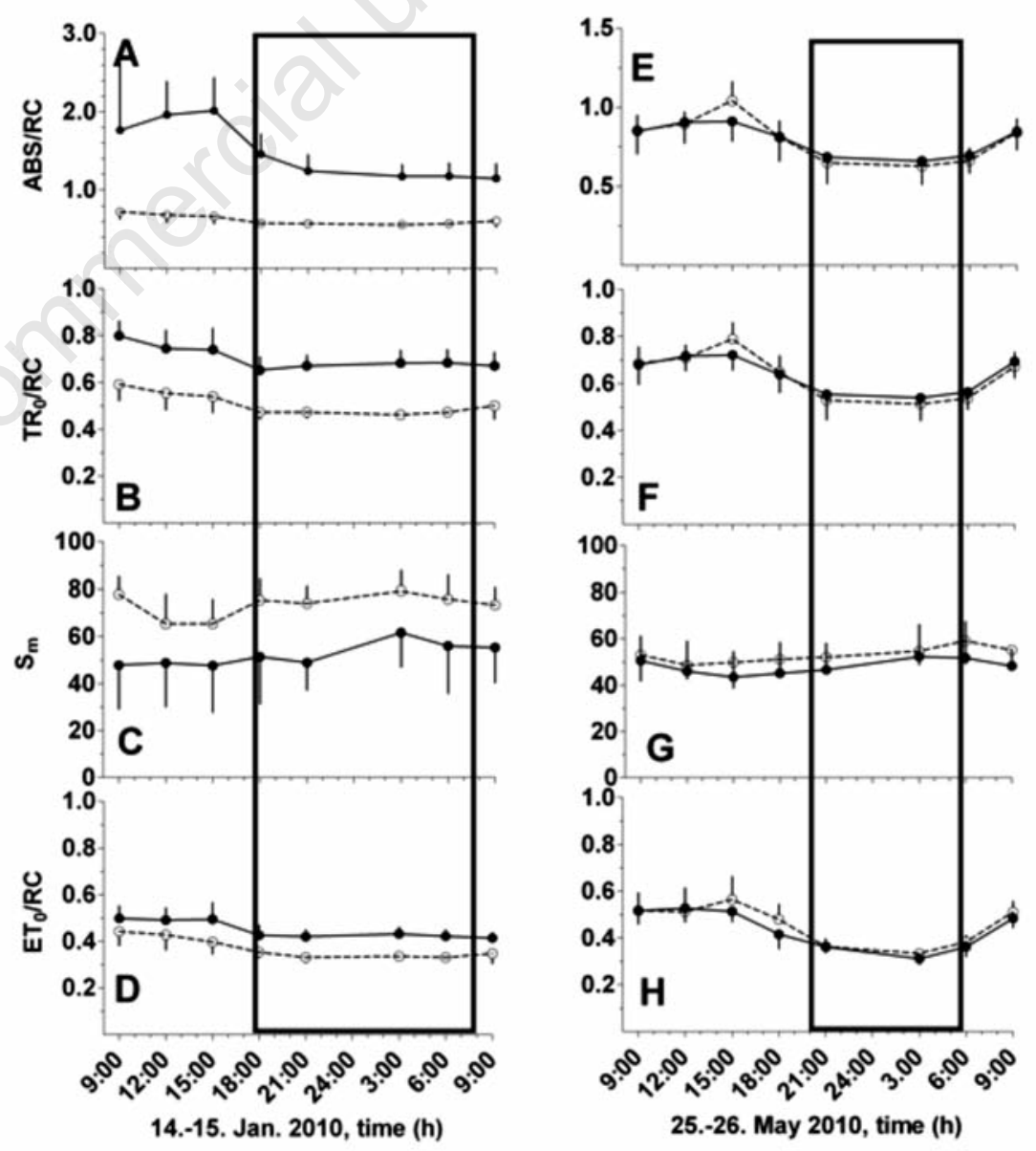

Figure 2. Diurnal courses of chl fluorescence parameters in $Q$. ilex growing outdoors $(\bullet$, FR) or in a frost-free foliar greenhouse ( $\odot$, FRFF) at Frankfurt on 14.01.2010 (A-D) and on 25.05.2010 (E-H). FR, Frankfurt; FRFF, Frankfurt, frost-free (see also Figure 1). 
$\mathrm{ET}_{0} / \mathrm{RC}$ could be the effect of a lower electron pressure in the frost-treated plants due to a decrease of active (electron transporting) reaction centres as a consequence of both chronic and dynamic photoinhibition.

It is - in our eyes - notable that in the frostfree, but winter acclimated plants, the diurnal oscillation of the fluorescence parameters is diminished as compared to the plants in late May.

One possible explanation could be that the diurnal change in antenna size, reported by Liker and Garab ${ }^{26}$ relies on de novo synthesis of LHC proteins, which may be depressed under the lower winter temperatures.

\section{Semi-annual courses of energy dissipation and electron flow}

The unusually cold winter 2009/10 in Germany killed one out of six $Q$. ilex plants in the forest plantation and damaged another one severely. In the slightly milder city climate of Frankfurt, $Q$. ilex plants from the same batch remained unaffected. Larcher ${ }^{12,27}$ described the frost sensitivity of $Q$. ilex in his studies on the northernmost Italian population from Lake Garda and showed that $-17^{\circ} \mathrm{C}$ is $50 \%$ lethal to the buds and -26 to $-28^{\circ} \mathrm{C}$ are $50 \%$ lethal to the xylem and the sprout cambium, respectively. When outdoor winter temperatures decreased beyond $-5^{\circ} \mathrm{C}$, reversible extracellular freezing occurred in the $Q$. ilex leaves, and Fv/Fm values decreased strongly as a consequence of cytoplasm dehydration. ${ }^{27}$

He therefore considered $Q$. ilex a frost-tolerant species, in contrast to other (frost-avoiding) Mediterranean sclerophyllous plant species, which avoid leaf freezing by supercooling and are irreversibly damaged, once the temperature falls below this critical minimum threshold.

Presumably independent from this direct effect, several studies with punctual sampling during winter ${ }^{7,9-11}$ reported the occurrence of chronic photoinhibition at field sites in the Iberian Peninsula and in Central European city climate, when exposed to severe frosts and the same phenomenon is reported here. In the present study, the amount of sampling dates allowed a correlation of the data for maximum quantum yield of primary photochemistry of photosystem II in the dark-adapted state with the actual, preceding night temperatures and clearly indicated a significant correlation between these parameters in the range of -15 to $+10^{\circ} \mathrm{C}$ (Table 4 ). The same held true for the correlations between minimum temperature and predawn AZNAZ and energy dissipation of active RC (Table 4). It has been shown previously $^{8,28}$ that winter-induced increase of AZ/VAZ in overwintering, evergreen plant species is closely related to a decrease in Fv/Fm. We could corroborate this correlation
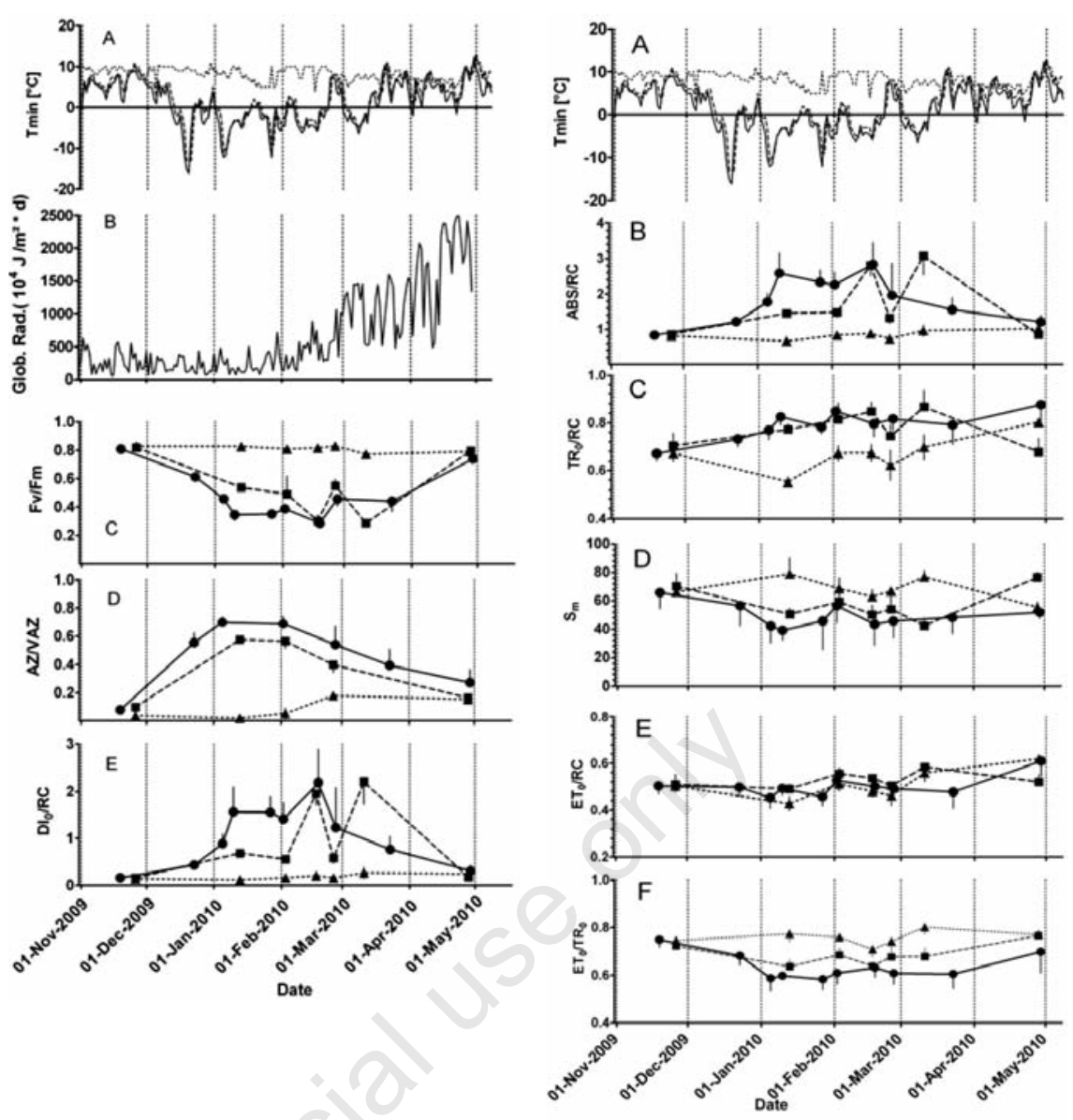

Figure 3. Semi-annual courses in winter of $T_{\min }(3 A)$, global radiation at Geisenheim (3B) and of maximum quantum yield of primary photochemistry (3C), AZ/VAZ (3D) and of the dissipation rate $\mathrm{DI}_{0} / \mathrm{RC}$ $(3 \mathrm{E})$ in $Q$. ilex growing outdoors at RU $(\bullet)$, FR $(\bullet)$ and FRFF $(\boldsymbol{\Delta})$. Daily minimum temperatures (3A) given for RU ( $)$, FR (....) and FRFF (....). Means $\pm S D, n=10(F v / F m)$ and 2 (AZ/VAZ) leaves per tree, respectively. Numbers of trees analysed were 6 in RU, 3 in FR and 4 in FRFF. A, anthera; $V$, viola; $Z$, zeaxanthin; FR, Frankfurt; FRFF, Frankfurt, frost-free; RU, Rüsselsheim; Fv/Fm, maximum quantum yield of primary photochemistry.

statistically over the winter period and extend it to the correlation between the parameters pre-dawn AZ/NAZ and $\mathrm{DI}_{0} / \mathrm{RC}$. The latter finding enhances the interpretation given in Adams et al., ${ }^{8}$ that sustained high AZNAZ ratios - independent of irradiation - may function as protective mechanisms in overwintering evergreens to prevent PS damage by excessive light in the early morning at subzero temperatures.

The analysis of the exciton/electron flow components showed, that the chronic photoinhibition period between mid December 2009 and mid-March 2010, which was modulated by the warm period at the end of February 2010 $T_{\text {min }}$ (4A) and of the OJIP-parameters $\mathrm{ABS} / \mathrm{RC}(\mathrm{4B})$, trapping efficiency $\mathrm{TR}_{0} / \mathrm{RC}$ (4C), $S_{m}(4 D)$, electron transport efficiency $\mathrm{ET}_{0} / \mathrm{RC}(4 \mathrm{E})$, and electron transport probability $\mathrm{ET}_{0} / \mathrm{TR}_{0}(4 \mathrm{~F})$ in $Q$. ilex growing outdoors at RU (•), FR (•) and FRFF $(\boldsymbol{A})$. Daily minimum temperatures (3A) given for RU ( (.....). Means $\pm \mathrm{SD}, \mathrm{n}=10$ leaves per tree. Numbers of trees analysed were 6 in RU, 3 in FR and 4 in FRFF. ABS, absorption rate; $\mathrm{RC}$, reaction centre; $\mathrm{TR}_{0}$, trapping rate; $\mathrm{ET}_{0}$, electron transport rate; RU, Rüsselsheim; FR, Frankfurt; FRFF, Frankfurt, frost-free.

and the high light / frost period at begin of March (cf. data points for FR on March $11^{\text {th }}$ ), was accompanied by a reversible strong increase of the $\mathrm{ABS} / \mathrm{RC}$ and $\mathrm{DI}_{0} / \mathrm{RC}$ ratios. Energy dissipation under these conditions is mainly due to AZ/NAZ-mediated heat emission from the antennae, a minor amount only due to fluorescence. ${ }^{8}$ Lehner and Lütz $^{29}$ found decreased $\mathrm{Fv} / \mathrm{Fm}$ and increased $\mathrm{ABS} / \mathrm{RC}$ values at a single date in February in two Pinus spp. from the alpine timberline. Unfortunately, at that time they did not calculate the dissipation flux from their data, but it can reasonably be
Figure 4. Semi-annual courses in winter of 
assumed, that in these Pinus spp. similar processes as in $Q$. ilex occurred, i.e. a AZNAZmediated downregulation of PS II, which lead to a decrease in active reaction centres and an increase in heat dissipation capacity - independent of a light-driven $\mathrm{pH}$ gradient. Trapping $\left(\mathrm{TR}_{0} / \mathrm{RC}\right)$ and electron transport $\left(\mathrm{ET}_{0} / \mathrm{RC}\right)$ flows showed only minor differences between the frost-exposed and the frost-free plants. Similar results were reported for Pinus cembra under severe frost at one representative winter date. ${ }^{30}$

Since the fluorescence kinetic-derived parameters only take the active reaction centres into account, ${ }^{21}$ and since the $\mathrm{ABS} / \mathrm{RC}$ and $\mathrm{DI}_{0} / \mathrm{RC}$ parameters reacted quite fast to the intermittent warming by the end of February, we conclude that their increase was not the (unlikely) result of a frost-associated increase of absorbance capacity. Instead, we suggest that a decrease of available active reaction centres due to downregulation and inactivation of the majority of the reaction centres occurred (Figure 4D). ${ }^{8,31}$ The analysis of the electron transport probability $\left(\mathrm{ET}_{0} / \mathrm{TR}_{0}\right)$ showed a moderate depression of the latter during the period of chronic photoinhibition, consistent with the rationale brought forward by Force $e t a l{ }^{22}$ on the expected effects of photoinhibition. From their experiments with isolated intact and broken chloroplasts and photoinhibited leaves, they concluded that decreases in the $\mathrm{ET}_{0} / \mathrm{TR}_{0}$ fluorescence parame-

ter are indicative of impaired $Q_{A}^{-}$reoxidation, presumably the result of impaired binding of $\mathrm{Q}_{\mathrm{B}}$ to the D1 protein. ${ }^{32}$ Hence, while the frost effects on energy dissipation $\left(\mathrm{DI}_{0} / \mathrm{RC}\right)$ and on predawn AZ/NAZ were large, whereas the effect on electron transport probability $\left(\mathrm{ET}_{0} / \mathrm{TR}_{0}\right)$ was significant, but small, we probably see two more or less independent sides of chronic photoinhibition on the photosynthetic apparatus and the observed significant correlation between AZ/VAZ and $\mathrm{ET}_{0} / \mathrm{TR}_{0}$ may well be correlative, but not causal. It might therefore well be worthwhile to compare the correlations between $\mathrm{DI}_{0} / \mathrm{RC}, \mathrm{ET}_{0} / \mathrm{TR}_{0}$ and $\mathrm{AZ} / \mathrm{NAZ}$ in both chronically and dynamically photoinhibited $Q$. ilex leaves in future experiments.

As already found during the diurnal measurements in Figure 2, $\mathrm{S}_{\mathrm{m}}$ increased throughout winter in FRFF plants, but not in the frostexposed plants (Figure 4), leading to a nearly twofold difference between FRFF and RU plants on some sampling days during the frost period (Jan14 Mar). Griffith et al. ${ }^{33}$ and Gray et $a l .{ }^{34}$ have shown, that the total plastoquinone (PQ) pool in winter rye thylakoids acclimates to shifts in electron pressure (i.e. it can increase twofold under high excitation pressure). During leaf senescence, the photosynthetically active $P Q$ pool size decreases significantly within one or two weeks. ${ }^{35}$ Since chloroplasts can contain at least three popula- tions of $\mathrm{PQ}$ [i.e. a fast reducible pool in granal thylakoids, a slowly reducible $\mathrm{PQ}$ pool in stromal thylakoids, and a (usually non-reducible) storage pool in plastoglobuli, ${ }^{36}$ it can be hypothesized, that acclimation processes of the fast reducible $P Q$ pool size towards experienced redox pressure can occur within limited time, i.e. a few days. $S_{\mathrm{m}}$ might then be regarded as a memory index of the preceding redox poise of the $P Q$ pool. In our case, from January to March, the redox poise in the FRFF plants may have been higher than in the field sites, because the FR and RU plants showed a 10-fold or more increased amount of energy dissipation as heat instead of electron transport into the ET chain due to their chronic photoinhibition (Figure 3E).

The intermittent increase of $S_{m}$ at the FR site in late April (in late May, their $S_{m}$ values equalled those of the FRFF plants again, Figure 2) possibly was due to a specific high light and low morning temperature situation in the unshaded experimental field on the days preceding the measurements. However, to substantiate the interpretation of the $S_{\mathrm{m}}$ data as a memory index of the preceding redox pressure on the electron transport chain, additional experiments would be necessary, e.g. by differential shading and independent assessment of the redox state of the $P Q$ pool during the days preceding the pre-dawn OJIP measurements.

\section{Conclusions}

In summary, we present conclusive evidence that the Mediterranean broadleaf evergreen species $Q$. ilex shows the competence for similar photoprotective behaviour with continuously increasing AZNAZ and downregulation of PS II under severe, long-lasting Central European frost periods as it is known from species from the alpine timberline. We suggest that $Q$. ilex may, from this point of view, have the potential to be considered a potential forestry tree species for future forestation experiments in warm, dry Central European stands, e.g. in mixed plantations with other Central and South European drought tolerant species to minimize the economic risks of Climate Change. However, since part of the plants at the Rüsselsheim experimental site was damaged by the severe frost in the winter of 2009/10, direct frost effects on the stems (i.e. on meristematic tissue and on water transport properties) may be limiting the frost tolerance of the aboveground parts of $Q$. ilex and only a few degrees difference in minimum temperature between the city climate and the forest climate may be crucial for (aboveground) survival. It should be recalled - in this context - that $Q$. ilex trees in parks in the city climate in Frankfurt have survived and been well growing for 60 or more years. ${ }^{7}$ Since $Q$. ilex is a diffuse porous species, ${ }^{37}$ which uses the same vessels for several years, embolism damage due to xylem freezing in young plants with low stem diameter at temperatures of $18^{\circ} \mathrm{C}$ or lower may strongly influence the survival rates, independent of damage to the photosynthetic apparatus. ${ }^{12,38,39}$ Repair mechanisms of such frost-induced embolism event ${ }^{38}$ may not be sufficient in individual plants and these effects as well as possible ecotype gradients of frost tolerance within the species depending on geographical provenience should be taken into account and analysed in future experiments.

\section{References}

1. Breckle S-W. Moglicher Einfluss des Klimawandels auf die Waldvegetation Nordwestdeutschlands? LÖBF-Mitt. 2005;30: 19-24. Available from: http://www.lanuv.nrw. de/veroeffentlichungen/loebf/loebf_mitteilungen/2005/loebfmi t_200502.pdf.

2. Walther GR, Post E, Convey P, et al. Ecological responses to recent climate change. Nature 2002;416: 389-95.

3. Lucht W, Schaphoff S, Erbrecht T, et al. Terrestrial vegetation redistribution and carbon balance under climate change. Carb Balance Managem 2006;1:6-13.

4. Malcolm JR, Markham A, Neilson RP, Garaci M. Estimated migration rates under scenarios of global climate change. J Biogeogr 2002;29:835-49.

5. Schmiedinger A., Bachmann M., Kölling C., Schirmer R. How to select tree species for trials against the background of climate change. Forstarchiv 2009;80:15-22.

6. Marris E. Planting the forest of the future. Nature 2009;459:906-8.

7. Brüggemann W, Bergmann M, Nierbauer K-U, et al. Photosynthesis studies on European evergreen and deciduous oaks grown under Central European climate conditions. II. Photoinhibitory and lightindependent Viola-xanthin deepoxidation and downregulation of photosystem II in evergreen, winter-acclimated European Quercus taxa. Trees 2009; 23:1091-100.

8. Adams WW III, Zarter R, Ebbert V, Demmig-Adams B. Photoprotective strategies of overwintering evergreens. BioScience 2004;54: 41-9.

9. Corcuera L, Morales F, Abadia A, GilPelegrin E. Seasonal changes in photosynthesis and photoprotection in a Quercus ilex subsp. ballota woodland located in its upper altitudinal extreme in the Iberian Peninsula. Tree Physiol 2005;25:599-608.

10. Oliveira G, Penuelas J. Comparative photo- 
chemical responses to winter stress of an evergreen (Quercus ilex L.) and a semideciduous (Cistus albidus L.) Mediterranean woody species. Acta Oecol 2000;21:2,97-107.

11. Martinez-Ferri E, Manrique E, Valladares F, Balaguer L. Winter photoinhibition in the field involves different processes in four co-occurring Mediterranean tree species. Tree Physiol 2004;24:981-90.

12. Larcher W. Zunahme des Frostabhärtungsvermögens von Quercus ilex im Laufe der Individualentwicklung. Planta 1969;88:130-5.

13. Strasser RJ, Srivastava A, Tsimilli-Michael M. The fluorescence transient as a tool to characterize and screen photosynthetic samples. In: Yunus M, Pathre U, Mohanty $P$ (eds). Probing photosynthesis: mechanisms, regulation and adaptation. London: Taylor and Francis; 2000. pp 445-483.

14. Hermans C, Smeyers M, Rodriguez RM, et al. Quality assessment of urban trees: a comparative study of physiological characterisation, airborne imaging and on site fluorescence monitoring by the 0JIP-test. J Plant Physiol 2003;160:81-90.

15. Bussotti F, Strasser RJ, Schaub M. Photosynthetic behavior of woody species under high ozone exposure probed with the JIP-test: a review. Environm Pollut 2007;147: 430-7.

16. Bussotti F, Desotgiu R, Cascio C, et al. Ozone stress in woody plants assessed with chlorophyll a fluorescence. A critical reassessment of existing data. Environm Exp Bot 2011;73:19-30.

17. Rapacz M, Wozniczka A. A selection tool for freezing tolerance in common wheat using the fast chlorophylla fluorescence transient. Plant Breeding 2009;128:227-34.

18. Rapacz M. Chlorophyll a fluorescence transient during freezing and recovery in winter wheat. Photosynthetica 2007;45:40918.

19. Garcia-Plazaola JI, Artetxe U, Becerril JM. Diurnal changes in antioxidant and carotenoid composition in the Mediterranean sclerophyll tree Quercus ilex (L) during winter. Plant Sci 1999;143:125-33.

20. Van Heerden PDR, Swanepoel JW, Krüger GHJ. Modulation of photosynthesis by drought in two desert scrub species exhibiting C3-mode CO2 assimilation. Env
Exp Bot 2007;61:124-36.

21. Strasser RJ, Tsimilli-Michael M., Srivastava A. Analysis of the fluorescence transient. In: George C, Papageorgiou C, Govindjee, eds. Chlorophyll fluorescence: a signature of Photosynthesis. Advances in photosynthesis and respiration series (Govindjee, Series Ed.) Dordrecht: Kluwer Academic Publ.; 2004. pp 321-362.

22. Force L, Critchley C, van Rensen JJS. New fluorescence parameters for monitoring photosynthesis in plants 1 . The effect of illumination on the fluorescence parameters of the JIP-test. Photosynth Res 2003;78:17-33.

23. de las Rivas J, Abadia A, Abadia J. A new reversed phase-HPLC method resolving all major higher plant photosynthetic pigments. Plan Physiol 1989;91;190-2.

24. Färber A, Young AJ, Ruban AV, et al. Dynamics of xanthophyll-cycle activity in different antenna subcomplexes in the photosynthetic membranes of higher plants. Plant Physiol 1997;115:1609-18.

25. Spearman C. Demonstration of formulae for true measurement of correlation. Amer J Psychol 1907;18:161-9.

26. Liker E, Garab G. Diurnal fluctuation in the composition of chlorophyll $a / b$ light harvesting antenna of photosystem II in young wheat leaves. Physiol Plant 1995;93:187-90.

27. Larcher W. Temperature stress and survival ability of Mediterranean sclerophyllous plants. Plant Biosyst 2000;134:279-95.

28. Verhoeven AS, Adams WW III, DemmigAdams B, et al. Xanthophyll cycle pigment localization and dynamics during exposure to low temperatures and light stress in Vinca major. Plant Physiol 1999;120:727-37.

29. Lehner G, Lütz C. Photosynthetic functions of cembran pines and dwarf pines during winter at timberline as regulated by different temperatures, snowcover and light. J Plant Physiol 2003;160:153-66.

30. Stecher G, Schwienbacher F, Mayr S, Bauer H. Effects of winter-stress on photosynthesis and antioxidants of exposed and shaded needles of Picea abies (L.) Karst, and Pinus cembra L Phyton 1999;39:20512.

31. Egerton JJG, Banks JCG, Gibson A, et al. Facilitation of seedling establishment: reduction in irradiance enhances winter growth of Eucalyptus pauciflora. Ecology 2000; 81:1437-49.

32. Briantais JM, Ducruet M, Hodges M, Krause GH. The effects of low temperature acclimation and photoinhibitory treatments on photosystem 2 studied by thermoluminescence and fluorescence decay kinetics. Photosynth Res 1992;31:1-10.

33. Griffith M, Elfman B, Camm EL. Accumulation of plastoquinone A during low temperature growth of winter rye. Plant Physiol 1984;74:727-9.

34. Gray GR, Ivanov AG, Krol M, Huner NPA. Adjustment of thylakoid plastoquinone content and Photosystem I electron donor pool size in response to growth temperature and growth irradiance in winter rye (Secale cereale L.). Photosynth Res 1998;56:209-21.

35. Prakash JSS, Srivastava A, Strasser RJ, Mohanty P. Senescence-induced alterations in the photosystem II functions of Cucumis sativus cotyledons: probing of senescence driven alterations of photosystem II by chlorophyll a fluorescence induction 0-J-I-P transients. Ind $\mathrm{J}$ Biochem Biophys 2003;40: 160-8.

36. Kruk J, Karpinski S. An HPLC-based method of estimation of the total redox state of plastoquinone in chloroplasts, the size of the photochemically active plastoquinone-pool and its redox state in thylakoids of Arabidop-sis. Biochim Biophys Acta 2006;1757:1669-75.

37. Tognetti R, Longobucco A, Raschi A. Vulnerability of xylem to embolism in relation to plant hydraulic resistance in Quercus pubescens and Quercus ilex cooccurring in a Mediterranean coppice stand in central Italy. New Phytol 1998;139:437-47.

38. LoGullo MA, Salleo S. Different vulnerabilities of Quercus ilex L. to freeze- and summer drought-induced xylem embolism: an ecological interpretation. Plant Cell Environm 1993;16:511-9.

39. Cavender-Bares J, Cortes P, Rambal S, et al. Summer and winter sensibility of leaves and xylem to minimum freezing temperatures: a comparison of co-occuring Mediterranean oaks that differ in leaf lifespan. New Phytol 2005;168:597-612. 